\title{
Effect of intrauterine infusion of an organic-certified product on uterine health, survival, and fertility of dairy cows with toxic puerperal metritis
}

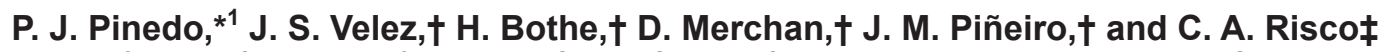 \\ ${ }^{\star}$ Texas A\&M AgriLife Research \& Extension Center, College of Veterinary Medicine and Biomedical Sciences, Texas A\&M University System, \\ Amarillo 79106 \\ †Aurora Organic Dairy, Platteville, CO 80651-9008 \\ ¥College of Veterinary Medicine, University of Florida, Gainesville 32610-0136
}

\begin{abstract}
The objective was to evaluate the effect of intrauterine infusion of an organic certified product (Optimum UterFlush, Van Beek Natural Science, Orange City, IA) on uterine health, survival, and fertility of cows affected with toxic puerperal metritis (TPM) in an organic dairy farm. Cows with TPM were defined as having an abnormally enlarged uterus and a fetid watery red-brown vaginal discharge, associated with systemic illness and fever (rectal temperature $\geq 39.5^{\circ} \mathrm{C}$ ), within $12 \mathrm{~d}$ postpartum. Cows diagnosed with TPM $(\mathrm{n}=220$; study d 0 ) were blocked by parity ( 1 and $\geq 2$ ) and randomly assigned into 1 of 2 intrauterine treatments applied every other day for a total of 3 applications: (1) control $(\mathrm{CON})=200 \mathrm{~mL}$ of povidone iodine diluted in $2 \mathrm{~L}$ of distilled water $(\mathrm{n}=113)$; (2) Optimum UterFlush (UF) $=3.75 \mathrm{~mL}$ diluted in $117 \mathrm{~mL}$ of distilled water $(\mathrm{n}=$ 107). All enrolled cows received hypertonic saline solution (500 mL $7.2 \%$ i.v.), dextrose (500 mL 50\% i.v.), and oral aspirin ( 5 boluses/d). Outcome variables for treatment efficacy included fever and presence of fetid vaginal discharge at study d 6 and 14, survival at study d 6 and 14 and at 30 and 100 DIM, and reproductive performance. Control variables were parity, BCS at enrollment, calving season, and milk yield. Occurrence of fever at d 6 and 14 was not different between the 2 treatment groups. Presence of fetid vaginal discharge at d 6 and 14 was lower in cows treated with UF compared with cows in the CON group (10.7 vs. $28 \%$ and 1.1 vs. $9.1 \%)$. The odds (95\% confidence interval) for survival and remaining in the farm at study d 6 and 14 and at 30 and 100 DIM for cows in the UF treatment were 4.67 (1.38-15.8), 2.77 (1.25-6.10), 3.13 (1.22-8.02), and $2.82(1.38-5.71)$ times the odds of cows in the CON
\end{abstract}

Received October 6, 2014.

Accepted January 29, 2015.

${ }^{1}$ Corresponding author: ppinedo@ag.tamu.edu group, respectively. The odds of AI until 150 DIM and the interval from calving to first AI were not different between the 2 treatments. However, pregnancy was affected by treatment; the odds (95\% confidence interval) of pregnancy at the first AI, 150 DIM, and 300 DIM for cows treated with UF were 2.15 (1.05-4.40), 1.81 (1.04-3.15), and $1.92(1.09-3.38)$ times the odds of cows in the CON group, respectively. Days to pregnancy were similar in both treatment groups, but the number of artificial inseminations per pregnancy were different (2.69 vs. 2.02 for cows in the CON and UF treatments). Results indicate that cows with TPM administered intrauterine infusion of Optimum UterFlush had higher odds of recovering and improved reproductive performance compared with cows treated with povidone iodine.

Key words: puerperal metritis, organic, Optimum UterFlush

\section{INTRODUCTION}

Uterine diseases, such as metritis and endometritis, are highly prevalent in high-producing dairy cows and are associated with decreased pregnancy per AI, extended interval to pregnancy, and increased culling (Bartlett et al., 1986; Sheldon and Dobson, 2004; Gilbert et al., 2005; LeBlanc, 2008). In addition to economic losses consisting of $\$ 285$ per lactation (Kasimanickam et al., 2004), animal welfare is also compromised by uterine diseases; affected cows suffer from loss of appetite, often become dehydrated, and may also show signs of pain (Sheldon et al., 2006).

The incidence of metritis in dairy cows ranges from 10 to $36 \%$ (Santos et al., 2010; Chapinal et al., 2011), and the disorder is more frequently diagnosed during the first week postpartum (Sheldon et al., 2006). A more severe condition, toxic puerperal metritis (TPM), defined as an acute systemic illness due to infection of the uterus with bacteria, usually within $21 \mathrm{~d}$ after parturition (Sheldon et al., 2006), is a life-threatening condition affecting a significant number of cows. 
In recent years the number of organic dairies has increased in North America (McBride and Greene, 2009). Organic dairy farms face strict prohibition in the use of antimicrobials, resulting in a reduced availability of therapies for treatment of metritis. In the United States, animals receiving antibiotic compounds are permanently disqualified from organic production (Pol and Ruegg, 2007; Ruegg, 2009), whereas in Canada dairy animals can undergo a limited number of emergency treatments per year (National Standard of Canada, 2013). As a result, alternative medications improving recovery rates in cows affected with TPM would be of substantial benefit to organic dairies. Botanical preparations have been proposed as alternative therapies for the treatment of disease in cattle (Ruegg, 2009); however, controlled studies on their clinical effects in veterinary medicine are limited. Optimum UterFlush (Van Beek Natural Science, Orange City, IA) is an Organic Materials Review Institute (Eugene, OR)-listed natural product recommended for use in organic operations during the postpartum period to help maintain or restore normal uterine environment. The preparation is for intrauterine administration and the active ingredient is carvacrol (4-isopropyl-2-methylphenol), which is a monoterpenic phenol produced by aromatic plants, including oregano. Carvacrol has been reported to exhibit numerous bioactivities including antioxidative, anti-inflammatory, and antibacterial properties (Baser, 2008; Friedman, 2014; Suntres et al., 2015). The mechanism of carvacrol's antimicrobial effect is not fully understood, but depletion of the intracellular ATP pool, a change in membrane potential, and an increase in the permeability of the cytoplasmic membrane for protons and potassium ions have been reported (Friedman, 2014). Conversely, the regulation of the expression of multiple cytokines is the proposed mechanism explaining the anti-inflammatory properties of carvacrol (Lima et al., 2013; Friedman, 2014).

Given the limited resources for treating TPM in organic dairies, evaluating the effect of this product on uterine health, survival, and fertility of cows with TPM in a controlled experiment is attractive. Increasing the availability of natural preparations that help in the recovery of cows affected by disorders such as TPM would be highly beneficial for organic systems. Relevant variables for evaluation of treatment efficacy should include clinical cure, as well as measures of economic significance, such as reproductive performance. Consequently, the objective was to evaluate the effect of intrauterine infusion of an organic certified product (Optimum UterFlush) on uterine health, survival, and fertility of cows affected with TPM in an organic dairy farm.

\section{MATERIALS AND METHODS}

The West Texas A\&M University Institutional Animal Care \& Use Committee approved the animal related procedures in this study (\#03-12-12).

\section{Study Population}

The study population consisted of cows from a single large organic dairy farm (7,150 milking cows) located in the Texas panhandle. The herd was a USDA-certified organic herd under the National Organic Program with cows housed in freestall barns with sand-bedded stalls. Primiparous and multiparous cows were grouped together. Cows were milked thrice daily and milk yield was measured and recorded monthly for individual cows. The rolling herd average milk production was $8,600 \mathrm{~kg}$ and the reported voluntary waiting period was $45 \mathrm{~d}$. Cows were fed a TMR twice a day to meet or exceed the nutritional requirements for a lactating Holstein cow producing $40 \mathrm{~kg} / \mathrm{d}$ of milk with $3.5 \%$ fat and $3.1 \%$ true protein (NRC, 2001). Diet was based on corn silage, alfalfa hay, concentrate, and pasture. During the grazing season (May to September), cows had access to pasture and grazing provided a significant portion of the total ration.

\section{Postpartum Health-Monitoring Program}

Cows were monitored daily between 0600 and 0800 $\mathrm{h}$, following the morning milking, for general health from calving to $12 \mathrm{~d}$ after parturition. Main parameters considered were appetite, appearance (depressed, dehydrated, and so on), and characteristics of vaginal discharge. Cows that appeared abnormal in any of these parameters were submitted for clinical examination by a veterinarian. At examination, all animals were evaluated for body condition using a 5-point (1 $=$ emaciated to $5=$ obese) system (Ferguson et al., 1994) and inspected for vaginal discharge by transrectal palpation and vaginal discharge inspection using the Metricheck device (Metricheck, SimcroTech, Hamilton, New Zealand). Vaginal discharge was scored according to Chenault et al. (2004) as $0=$ no discharge observed; $1=$ not fetid, normal lochia (viscous; red, brown, or clear); $2=$ not fetid, thick mucus, cloudy, clearing, or clear; 3 = not fetid, may be purulent, mucopurulent, or chocolate brown; or $4=$ fetid, may be red or pink to chocolate brown, thin, serous, and watery, with or without pieces of necrotic tissue. Per-rectum palpation was conducted to establish a uterine score (UTS; modified from Zemjanis, 1970). Uterine score considered the size and tonicity of the uterus at the greater curvature 
of the uterine horn $(1=$ flaccid uterus larger than 1 hand, $2=$ uterus with moderate-to-high tonicity and smaller than 1 hand). Rectal temperature (RT) was measured using an electronic thermometer (GLA Agricultural Electronics, San Luis Obispo, CA). The time of diagnosis was considered study d 0 and corresponded with the start of treatment.

\section{Reproductive Management}

Cows enrolled in the study were subject to a reproductive program based on insemination from visual estrus detection. Cows' tailheads were painted daily with color chalk and checked for estrus by removal of tail chalk. If estrus was determined, cows were AI during the morning. None of the cows were subjected to any type of estrus or ovulation synchronization protocol. Voluntary waiting period was $45 \mathrm{~d}$ and pregnancy was diagnosed by transrectal palpation at $60 \mathrm{~d}$ after AI.

\section{Case Definition and Treatment Allocation}

All cows calving between August 2012 and June 2013 and affected with TPM between d 1 and 12 after calving were eligible for enrollment. Cows with TPM were defined as having an abnormally enlarged uterus and a vaginal discharge score (VDS) of 4, associated with signs of systemic illness (decreased milk yield, dullness, or other signs of toxemia) and fever $\left(\mathrm{RT} \geq 39.5^{\circ} \mathrm{C}\right)$ within $12 \mathrm{~d}$ postpartum (Sheldon et al., 2006). Cows that were concurrently affected by any health disorder other than uterine conditions at the time of enrollment were excluded from the study. In addition, cows that had a Caesarian section, fetotomy, or uterine prolapse were not considered. Consequently, the following criteria were required for cows to be enrolled in the study: $\leq 12$ d postpartum, $\mathrm{RT} \geq 39.5^{\circ} \mathrm{C}, \mathrm{VDS}=4$, signs of systemic illness, and absence of exclusion criteria.

Two hundred twenty lactating Holstein cows (136 primiparous and 84 multiparous) affected with TPM were randomly assigned into 1 of 2 intrauterine (i.u.) treatment groups (control and experimental) at the time of diagnosis. The treatment allocation was blocked by parity $(1$ and $\geq 2)$ and based on sequence of diagnosis. Due to well-being considerations, a nontreated control group was not included. Consequently, the reference control group $(\mathbf{C O N})$ received the operational procedures for treatment of TPM for the study farm. Treatments were applied every other day for a total of 3 times as follows: (1) CON = intrauterine infusion of $200 \mathrm{~mL}$ of povidone iodine diluted in $2 \mathrm{~L}$ of distilled water $(\mathrm{n}=113)$; (2) Optimum UterFlush $(\mathbf{U F})=$ i.u. infusion of $3.75 \mathrm{~mL}$ diluted in $117 \mathrm{~mL}$ of distilled water (as specified by the manufacturer, $\mathrm{n}=107$ ). According to the study farm health protocols, all treated cows received hypertonic saline solution (500 $\mathrm{mL}, 7.2 \%$ i.v.), dextrose $(500 \mathrm{~mL}, 50 \%$ i.v.), and oral aspirin [5 boluses (15.6 g of acetylsalicylic acid/bolus) per day]. In addition, all enrolled cows had their body condition scored (Ferguson et al., 1994) at enrollment.

A group of 400 healthy cows calving during the same period without any postpartum disorder was enrolled as a healthy control (HC) group to serve as reference for comparing survival and reproductive parameters with cows in the CON and UF groups. A parity distribution similar to that of the study groups was established and the selection of cows within parity category was made at random using a random number generator.

\section{Monitoring, Events of Interest, and Independent Variables}

Enrolled cows had RT measured during the morning (0600-0800 h) from d 0 to 6 . A complete clinical examination by a veterinarian was performed at $\mathrm{d} 6$ and 14 . Outcome variables for treatment efficacy included fever $\left(\mathrm{RT} \geq 39.5^{\circ} \mathrm{C}\right.$ ), presence of fetid vaginal discharge (VDS $=4)$, and uterine size and tonicity $(\mathrm{UTS}=1)$ at study d 6 and 14. Clinical cure was considered as the combination of absence of fever and VDS $<4$ (Chenault et al., 2004). Survival at study d 6 and 14 and at 30 and 100 DIM as well as reproductive performance (percentage of cows AI at 150 and 300 DIM; day to first AI; pregnancy at first AI; percentage of pregnant cows at 150 and 300 DIM) were also evaluated. Veterinarians responsible for clinical examinations were blinded to allocation groups and the nature of treatments. Health evaluation was performed considering fever, VDS, UTS, and clinical cure. Control variables included parity ( 1 or $\geq 2$ ), BCS at enrollment $(\leq 2.5$ or $>2.5)$, calving season, and average milk yield during the first 8 wk of lactation.

\section{Bacteriological Cultures}

Due to limited resources, uterine fluid samples were collected in a subgroup of the study cows to characterize the bacterial population at the time of enrollment $(\mathrm{n}=115)$ and at clinical examination on d $14(\mathrm{n}=41)$. The sample collection was completed during visits to the farm across the whole study period and performed following thorough sanitation of the vulva and entrance of the vagina by using a sterile plastic catheter and aspirating uterine fluid using a $20-\mathrm{mL}$ sterile disposable syringe. The fluid was transferred into sterile tubes, captured by a sterile swab, and inoculated into a BD BBL prepared culture medium (Becton, Dickinson and 
Company, Franklin Lakes, NJ). Samples were submitted to a commercial laboratory for bacterial speciation (Texas A\&M Veterinary Medical Diagnostic Laboratory, Amarillo, TX).

\section{Statistical Analysis}

The experimental design was a randomized block design with TPM cows blocked by parity and randomly assigned to 1 of the 2 treatments. The sample size was calculated to detect a difference of 20 percentage points in the health parameters evaluated (clinical cure: absence of fever at d 14 and VDS <4) in favor of the experimental group (UF) compared with the reference treatment $(\mathrm{CON})$. A cure rate for cows in the $\mathrm{CON}$ group of $50 \%$ was anticipated. Considering power of $80 \%$ and confidence of $95 \%$, the number of cows required to show a significant difference between the 2 treatments was estimated in 82 per group. Sample size calculations were performed using the PROC POWER procedure of SAS (release 9.2; SAS Institute Inc., Cary, $\mathrm{NC})$.

Logistic regression (PROC GLIMMIX) was used for the analysis of binary outcome variables, whereas continuous variables were evaluated by ANOVA (PROC GLM). The appropriate randomization of cows at the time of enrollment for discrete outcomes was analyzed by the Chi-squared test (PROC FREQ). Analyses of appropriate randomization for continue variables were performed by use of a Tukey test (LSMEANS statement). Univariate analyses were used to test the inclusion of each explanatory variable in the final models. Effects with $P \leq 0.20$ were included in the initial multivariable analysis and the final models were tested through a backward elimination procedure. The significance level for inclusion in the final model was set at $P \leq 0.10$ to account for potential confounders affecting both the response and the predictors. Treatment was forced in the final models and interactions between the effect of treatment and significant variables were considered.

The effect of treatment on daily RT was analyzed by repeated measures (repeated statement) and timeto-event analyses were performed for reproductive outcomes. Hazard distributions for time to first AI and pregnancy were calculated using the actuarial method of the LIFETEST procedure of SAS to test the null hypothesis that the survivor functions (time from calving to a reproductive event) were identical for the 2 groups receiving a different treatment. Additionally, a Cox proportional regression model was developed to evaluate the effect of multiple variables on the risk of AI and pregnancy (PROC PHREG). Statistical significance was set at $P \leq 0.05$.

\section{RESULTS}

\section{Descriptive Statistics}

Overall, 220 lactating Holstein cows (136 primiparous and 84 multiparous) diagnosed with TPM were enrolled in the study (CON and UF groups included 113 and 107 cows, respectively). Average (SEM) parity numbers were $1.89(0.12)$ and $1.51(0.09)$ for the CON and UF groups, respectively, whereas DIM at enrollment were $5.87(0.16)$ and $6.68(0.21)$ for the CON and UF groups. Average (SEM) BCS at enrollment were 2.87 (0.03) for CON and 2.75 (0.03) for UF. None of these variables were significantly different between treatment groups.

\section{Bacteriological Cultures}

The proportions for different bacteria isolated from a subpopulation of the study cows at enrollment $(\mathrm{n}=$ $115)$ and at $\mathrm{d} 14(\mathrm{n}=41)$ are summarized in Table 1. Main bacterial populations isolated were Trueperella pyogenes (69.5 and $65.8 \%$ at d 0 and 14, respectively) and Escherichia coli $(31.3$ and $7.3 \%$ at d 0 and 14 , respectively). The association between the occurrence of these 2 bacterial populations at $\mathrm{d} 0$ and health, survival, and reproductive outcomes was tested by multivariate logistic regression. Only 2 outcomes evidenced significant associations; presence of $E$. coli was associated with higher chances of culling at $\mathrm{d} 14$ [odds ratio $(\mathbf{O R})=7.76 ; 95 \% \mathrm{CI}=1.28-46.8]$ and lower odds of $\mathrm{AI}<150 \mathrm{DIM}(\mathrm{OR}=0.23 ; 95 \% \mathrm{CI}=0.05-0.81)$. When cows with paired samples at enrollment and d 14 were considered, only $5 / 16$ and $5 / 13$ cleared $T$. pyogenes infection in CON and UF groups, respectively $(P=0.9)$. In the case of E. coli, $5 / 5$ and $3 / 3$ cows with paired samples cleared infection in CON and UF groups, respectively $(P=1.0)$, but $1(\mathrm{CON})$ and 2 (UF) cows negative at enrollment were $E$. coli-positive at d 14 .

\section{Rectal Temperature, Vaginal Discharge Score, and Uterine Score}

A total of 203 and 181 cows were evaluated on study d 6 and 14, respectively. Thirteen (13 culled; 0 dead) and 4 (3 culled; 1 dead) cows from CON and UF groups, respectively, were not present at the farm at d 6 after enrollment. Subsequently, 25 (23 culled; 2 dead) and 14 (13 culled; 1 dead) cows from CON and UF groups, respectively, were not at the farm at d 14 evaluation. The main reasons for culling until 14 DIM were worsened metritis condition $(\mathrm{UF}=6 ; \mathrm{CON}=16)$, followed by low milk production and low body condition (UF $=4 ; \mathrm{CON}=5)$ and pneumonia $(\mathrm{UF}=2$ cows; $\mathrm{CON}$ $=2$ ). One cow was diagnosed with digestive problems 
Table 1. Distribution of the main bacteriological isolates from a subpopulation of the study cows at enrollment $(\mathrm{n}=115)$ and at study d 14 $(\mathrm{n}=41)$

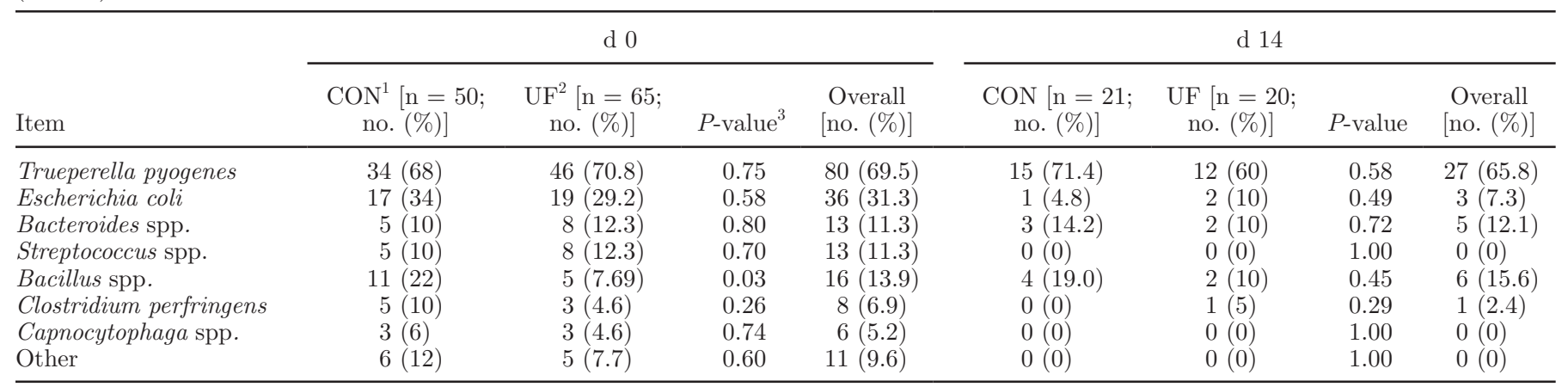

${ }^{1} \mathrm{CON}=$ control group, receiving $200 \mathrm{~mL}$ of povidone iodine diluted in $2 \mathrm{~L}$ of distilled water (i.u.).

${ }^{2} \mathrm{UF}=$ Optimum UterFlush (Van Beek Natural Science, Orange City, IA) group, receiving $3.75 \mathrm{~mL}$ diluted in $117 \mathrm{~mL}$ of distilled water (i.u.).

${ }^{3}$ As indicated by Chi-squared test.

$(\mathrm{CON})$. The findings from necropsy of dead cows were peritonitis $(\mathrm{CON})$ and metritis $(\mathrm{CON})$. No significant findings were found in a third cow (UF).

Average (SEM) RT at enrollment were 39.7 (0.03) and $39.8^{\circ} \mathrm{C}(0.03)$ for $\mathrm{CON}$ and $\mathrm{UF}$, respectively $(P=$ $0.18)$. At $\mathrm{d} 6,31.0$ and $20.4 \%$ of the cows in the CON and $\mathrm{UF}$ groups were febrile $\left(\mathrm{RT} \geq 39.5^{\circ} \mathrm{C}\right)$, respectively $(P=0.08)$. At $\mathrm{d} 14,8.0(\mathrm{CON})$ and $11.8 \%(\mathrm{UF})$ of the cows continued to be febrile $(P=0.38$; Table 2$)$. Daily variation in RT from enrollment to d 6 by treatment group is presented in Figure 1. The repeated measures analysis indicated a significant effect on RT for time (study day $P=0.0001$ ). In spite of differences in RT at some time points, no overall effect was found for the day by treatment interaction $(P=0.14)$ and $\mathrm{RT}$ averages converged by d $14\left(38.9^{\circ} \mathrm{C}\right)$ in both groups. Likewise, the multivariate analyses indicated no significant effect for treatment on RT at d 6 and 14 (Table 3).

At study d 6, 28 and $10.7 \%$ of the cows in the CON and UF groups had VDS $=4$, respectively (Table 2). The multivariate analysis indicated a significant effect for treatment on VDS. The odds of VDS $=4$ for cows in the UF group were lower than those for cows in the $\mathrm{CON}$ group $(\mathrm{OR}=0.19 ; 95 \% \mathrm{CI}=0.09-0.45)$. Vaginal discharge score was also associated with calving season; the odds of VDS $=4$ in cows calving in spring were 0.10 times $(95 \% \mathrm{CI}=0.03-0.34)$ the odds of cows calving in winter. At d 14, 9.1 and $1.1 \%$ of the cows in the CON and UF groups had VDS $=4$, respectively. Cows in the UF group had lower odds of VDS $=4$ compared with cows in the CON group (Table 3 ; OR $=0.075 ; 95 \%$ CI $=0.009-0.63)$.

When both absence of fever and VDS $<4$ were combined (clinical cure), 48.7 (55/113) and 70.1\% (75/107) of the cows in the CON and UF groups had clinical cure at $\mathrm{d} 6$, respectively $(P=0.003)$. At $\mathrm{d} 14,65.5$ $(74 / 113)$ and $75.7 \%(81 / 107)$ of the cows in the CON
Table 2. Distribution of cows by category of outcome variable and treatment group (CON, $\mathrm{n}=113 ; \mathrm{UF}, \mathrm{n}=107)$ at $\mathrm{d} 6$ and $\mathrm{d} 14$ clinical examinations

\begin{tabular}{|c|c|c|c|}
\hline \multirow[b]{2}{*}{ Variable } & \multicolumn{2}{|c|}{ Treatment $^{1}$} & \multirow[b]{2}{*}{$P$-value 2} \\
\hline & $\begin{array}{c}\text { CON } \\
{[\text { no. }(\%)]}\end{array}$ & $\begin{array}{c}\text { UF } \\
{[\text { no. }(\%)]}\end{array}$ & \\
\hline \multicolumn{4}{|l|}{ d 6 clinical exam } \\
\hline Present in the farm & $100(88.5)$ & $103(96.2)$ & 0.03 \\
\hline $\begin{array}{l}\text { Fever }\left(\mathrm{RT} \geq 39.5^{\circ} \mathrm{C}\right) \\
\operatorname{VDS}^{3}\end{array}$ & $31(31.0)$ & $21(20.4)$ & 0.08 \\
\hline 1 & $1(1)$ & $1(0.97)$ & 0.01 \\
\hline 2 & $14(14)$ & $17(16.5)$ & \\
\hline 3 & $57(57)$ & $74(71.8)$ & \\
\hline 4 & $28(28)$ & $11(10.7)$ & \\
\hline \multicolumn{4}{|l|}{$\mathrm{UTS}^{4}$} \\
\hline 1 & $87(87)$ & $59(57.3)$ & 0.001 \\
\hline \multirow{2}{*}{\multicolumn{4}{|c|}{ d 14 clinical exam }} \\
\hline & & & \\
\hline Present in the farm & $88(77.9)$ & $93(86.9)$ & 0.08 \\
\hline Fever $\left(\mathrm{RT} \geq 39.5^{\circ} \mathrm{C}\right)$ & $7(8.0)$ & $11(11.8)$ & 0.38 \\
\hline \multicolumn{4}{|l|}{ VDS } \\
\hline 1 & $16(18.2)$ & $19(20.4)$ & 0.02 \\
\hline 2 & $40(45.5)$ & $43(46.2)$ & \\
\hline 3 & $24(27.3)$ & $30(32.3)$ & \\
\hline 4 & $8(9.1)$ & $1(1.1)$ & \\
\hline \multicolumn{4}{|l|}{ UTS } \\
\hline 1 & $35(39.8)$ & $15(16.3)$ & 0.004 \\
\hline 2 & $53(60.2)$ & $77(83.7)$ & \\
\hline
\end{tabular}

$\overline{{ }^{1} \mathrm{CON}}=$ control group, receiving $200 \mathrm{~mL}$ of povidone iodine diluted in $2 \mathrm{~L}$ of distilled water (i.u.); UF = Optimum UterFlush (Van Beek Natural Science, Orange City, IA) group, receiving $3.75 \mathrm{~mL}$ diluted in $117 \mathrm{~mL}$ of distilled water (i.u.).

${ }^{2}$ As indicated by Chi-squared test.

${ }^{3}$ Vaginal discharge score: $0=$ no discharge observed; $1=$ not fetid, normal lochia; 2 = not fetid; thick mucus; cloudy, clearing, or clear; 3 $=$ not fetid; may be purulent, mucopurulent, or chocolate brown; or $4=$ fetid.

${ }^{4}$ Uterine score: 1 = flaccid uterus larger than 1 hand; 2 = uterus with moderate-to-high tonicity and smaller than 1 hand. 
Table 3. Results from the multivariable logistic regression analyses by outcome variable at d 6 and d 14 after enrollment; only variables with $P<0.10$ are presented

\begin{tabular}{|c|c|c|c|}
\hline Variable & $\mathrm{OR}^{1}$ & $95 \% \mathrm{CI}$ & $P$-value \\
\hline \multicolumn{4}{|c|}{ d 6 after enrollment } \\
\hline \multicolumn{4}{|c|}{ Present in the farm } \\
\hline \multicolumn{4}{|c|}{ Treatment $^{2}$} \\
\hline UF & 4.67 & $1.38-15.8$ & 0.01 \\
\hline $\mathrm{CON}$ & Referent & - & - \\
\hline \multicolumn{4}{|c|}{ BCS at enrollment } \\
\hline$>2.5$ & 3.57 & $1.22-11.1$ & 0.03 \\
\hline$\leq 2.5$ & Referent & - & - \\
\hline \multicolumn{4}{|c|}{ Fever $\left(\mathrm{RT} \geq 39.5^{\circ} \mathrm{C}\right)$} \\
\hline \multicolumn{4}{|c|}{ Treatment } \\
\hline UF & 0.55 & $0.27-1.10$ & 0.09 \\
\hline \multirow{2}{*}{\multicolumn{4}{|c|}{ Calving season }} \\
\hline & & & \\
\hline Fall & 0.26 & $0.09-0.68$ & 0.03 \\
\hline Spring & 0.39 & $0.17-0.94$ & - \\
\hline Summer & 0.71 & $0.28-1.84$ & - \\
\hline Winter & Referent & - & - \\
\hline \multicolumn{4}{|l|}{$\mathrm{VDS}=4^{3}$} \\
\hline \multicolumn{4}{|l|}{ Treatment } \\
\hline UF & 0.198 & $0.09-0.45$ & 0.0001 \\
\hline $\mathrm{CON}$ & Referent & - & - \\
\hline \multicolumn{4}{|c|}{ Calving season } \\
\hline Fall & 1.03 & $0.41-2.60$ & 0.001 \\
\hline Spring & 0.10 & $0.03-0.34$ & - \\
\hline Summer & 0.53 & $0.18-1.59$ & - \\
\hline \multirow{2}{*}{\multicolumn{4}{|c|}{$\mathrm{UTS}=1^{4}$}} \\
\hline & & & \\
\hline \multicolumn{4}{|l|}{ Treatment } \\
\hline UF & 0.278 & $0.13-0.59$ & 0.0009 \\
\hline $\mathrm{CON}$ & Referent & - & - \\
\hline \multicolumn{4}{|c|}{ Calving season } \\
\hline Fall & 0.815 & $0.34-1.96$ & 0.001 \\
\hline Spring & 5.088 & $1.46-17.7$ & - \\
\hline Summer & 0.399 & $0.15-1.05$ & - \\
\hline Winter & Referent & - & - \\
\hline \multicolumn{4}{|c|}{ d 14 after enrollment } \\
\hline \multicolumn{4}{|c|}{ Present in the farm } \\
\hline \multicolumn{4}{|c|}{ Treatment } \\
\hline UF & 2.77 & $1.25-6.10$ & 0.01 \\
\hline $\mathrm{CON}$ & Referent & - & - \\
\hline \multicolumn{4}{|c|}{ BCS at enrollment } \\
\hline$>2.5$ & 4.25 & $1.92-9.09$ & 0.0004 \\
\hline$\leq 2.5$ & Referent & - & - \\
\hline \multicolumn{4}{|l|}{$\mathrm{VDS}=4$} \\
\hline \multicolumn{4}{|l|}{ Treatment } \\
\hline UF & 0.075 & $0.009-0.63$ & 0.017 \\
\hline $\mathrm{CON}$ & Referent & - & - \\
\hline \multicolumn{4}{|l|}{$\mathrm{UTS}=1$} \\
\hline \multicolumn{4}{|l|}{ Treatment } \\
\hline UF & 0.31 & $0.01-0.64$ & 0.001 \\
\hline $\mathrm{CON}$ & Referent & - & - \\
\hline
\end{tabular}

${ }^{1}$ Odds ratio.

${ }^{2} \mathrm{UF}=$ Optimum UterFlush (Van Beek Natural Science, Orange City, IA) group, receiving $3.75 \mathrm{~mL}$ diluted in $117 \mathrm{~mL}$ of distilled water (i.u.); $\mathrm{CON}=$ control group, receiving $200 \mathrm{~mL}$ of povidone iodine diluted in $2 \mathrm{~L}$ of distilled water (i.u.).

${ }^{3}$ Vaginal discharge score: $0=$ no discharge observed; $1=$ not fetid, normal lochia; $2=$ not fetid; thick mucus; cloudy, clearing, or clear; 3 $=$ not fetid; may be purulent, mucopurulent, or chocolate brown; or $4=$ fetid.

${ }^{4}$ Uterine score: 1 = flaccid uterus larger than 1 hand; $2=$ uterus with moderate-to-high tonicity and smaller than 1 hand.

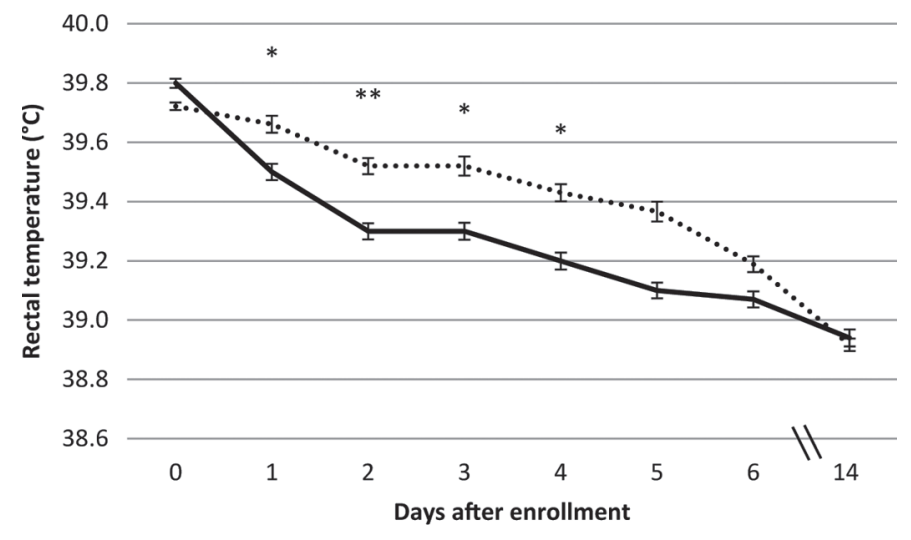

Figure 1. Rectal temperatures on d 0 to 6 and 14 after enrollment by treatment. The control group (...) received $200 \mathrm{~mL}$ of povidone iodine diluted in $2 \mathrm{~L}$ of distilled water (i.u.); the Optimum UterFlush (Van Beek Natural Science, Orange City, IA) group (-) received 3.75 $\mathrm{mL}$ diluted in $117 \mathrm{~mL}$ of distilled water (i.u.). Error bars represent SEM. ${ }^{* *} P<0.05 ;{ }^{*} P<0.10$.

and UF groups presented clinical cure, respectively $(P$ $=0.18)$.

Overall, the distribution of UTS at d 6 was significantly different for the 2 treatment groups [13.0 and $42.7 \%$ of cows with UTS $=2$ (high tonicity and smaller uterine size) in CON and UF groups, respectively]. An interaction of treatment by parity influenced the UTS. The significance of the effect of treatment persisted when only primiparous cows were considered: 10.0 and $47.8 \%$ of cows with UTS $=2$ for CON and UF groups, respectively. However, the difference was not significant for multiparous cows at d 6 (17.8 and $32.3 \%$ scored 2 for CON and UF, respectively; $P=0.13$ ). At $d 14$, the overall UTS distribution was different for the 2 treatment groups (60.2 and $83.7 \%$ UTS $=2$ for $\mathrm{CON}$ and UF, respectively). Again, the significance of this difference persisted in primiparous cows (55.1 and 87.5\% $\mathrm{UTS}=2$ for CON and UF, respectively; $P=0.0001$ ), but no significant difference was found for multiparous cows (66.7 and 75.0\% UTS $=2$ for CON and UF, respectively; $P=0.46)$.

\section{Survival}

Results from the multivariate logistic regression for each of the survival outcomes are presented in Tables 3 and 4 . The multivariate analysis indicated a significant effect for treatment on survival at d 6 after enrollment $(P=0.01)$. Cows in the UF group had higher odds of survival at d 6 compared with cows in the CON group $(\mathrm{OR}=4.67 ; 95 \% \mathrm{CI}=1.38-15.8)$. Survival at d 6 was also associated with BCS at enrollment; cows with BCS $>2.5$ had higher odds of survival compared with cows with low $\mathrm{BCS}(\mathrm{OR}=3.57 ; 95 \% \mathrm{CI}=1.22-11.1)$. 
Table 4. Results from the multivariable logistic regression analyses for survival at 30 and at 100 DIM; only variables with $P<0.10$ are presented

\begin{tabular}{lccc}
\hline Variable & OR $^{1}$ & $95 \%$ CI & $P$-value \\
\hline 30 DIM & & & \\
Present in the farm & & & \\
Treatment & & & \\
$\quad$ UF & & & \\
CON & 3.13 & $1.22-8.02$ & 0.001 \\
BCS at enrollment & Referent & - & - \\
$\quad \leq 2.5$ & 0.36 & $0.13-0.94$ & 0.04 \\
$>2.5$ & Referent & - & - \\
Calving season & & & \\
Fall & 1.18 & $0.45-3.13$ & 0.01 \\
Spring & 4.66 & $1.39-15.6$ & - \\
Summer & 6.89 & $1.32-35.9$ & - \\
Winter & Referent & - & - \\
100 DIM & & & \\
Present in the farm & & & \\
Treatment & & & \\
UF & 2.82 & $1.38-5.71$ & 0.004 \\
CON & Referent & - & - \\
BCS at enrollment & & & \\
$\quad \leq 2.5$ & 0.47 & $0.22-1.00$ & 0.05 \\
$\quad>2.5$ & Referent & - & - \\
Calving season & & & \\
Fall & 1.13 & $0.48-2.64$ & 0.04 \\
Spring & 3.85 & $1.43-10.31$ & - \\
Summer & 1.60 & $0.60-4.22$ & - \\
Winter & Referent & - & - \\
\hline
\end{tabular}

${ }^{1}$ Odds ratio.

${ }^{2} \mathrm{UF}=$ Optimum UterFlush (Van Beek Natural Science, Orange City, IA) group, receiving $3.75 \mathrm{~mL}$ diluted in $117 \mathrm{~mL}$ of distilled water (i.u.); $\mathrm{CON}=$ control group, receiving $200 \mathrm{~mL}$ of povidone iodine diluted in $2 \mathrm{~L}$ of distilled water (i.u.).

Contrary to the univariate analysis (Table 2), when control variables were included in the model, results indicated a significant effect for treatment on survival at d 14 after enrollment. Cows in the UF group had higher odds of survival at d 14 compared with cows in the CON group $(\mathrm{OR}=2.77 ; 95 \% \mathrm{CI}=1.25-6.10)$. Survival at d 14 was also associated with BCS at enrollment; cows with BCS $>2.5$ had higher odds of survival compared with cows with low BCS (OR $=4.25 ; 95 \%$ $\mathrm{CI}=1.92-9.09)$.

A total of 72.6 and $84.1 \%$ of the cows in the CON and UF groups, respectively, were still in the farm at 30 DIM, whereas $98 \%$ of the HC cows were in the herd at 30 DIM. The multivariate logistic regression analysis indicated a significant effect for treatment on survival at $30 \mathrm{~d}$ after calving; cows in the UF group had higher odds of survival at 30 DIM compared with cows in the CON group ( $\mathrm{OR}=3.13 ; 95 \% \mathrm{CI}=1.22-8.02)$. Survival at 30 DIM was also associated with BCS at enrollment $(P=0.04)$ and calving season $(P=0.01)$. Among the HC cows, $97 \%$ survived at least until d 100 after calving. In TPM cows, this variable was significantly af- fected by treatment, with 70.8 and $80.4 \%$ of the cows in the CON and UF groups present in the farm at 100 DIM. Cows in the UF group had higher odds of survival at 100 DIM compared with cows in the CON group $(\mathrm{OR}=2.82 ; 95 \% \mathrm{CI}=1.38-5.71)$. Similar to survival at 30 DIM, survival at 100 DIM was associated with BCS at enrollment and calving season.

\section{Reproductive Performance}

First AI. Overall, 56.6\% (64/113) of the cows in CON group received AI by 150 DIM. In the UF group, $61.7 \%(66 / 107)$ of the cows received at least 1 AI by 150 DIM, but this difference was not significant $(P=$ 0.27 ). Conversely, $93 \%$ of the cows in the HC group were bred by 150 DIM and this proportion was different from the CON and UF groups $(P<0.0001)$. The probability of being bred at $150 \mathrm{~d}$ was only associated with BCS at enrollment; cows with BCS $>2.5$ had higher odds of AI compared with cows with low BCS (OR = 2.40; $95 \%$ CI $=1.31-4.61$; Table 5). At 300 DIM, $61.1 \%$ (69/113) of the cows in CON group and $73.8 \%(79 / 107)$ of the cows in the UF group were bred and the effect of treatment was significant. Conversely, 95\% (373/393) of the $\mathrm{HC}$ cows had received at least one AI. There was a tendency toward significance for the effect of treatment on days from calving to first $\mathrm{AI}(\mathrm{CON}=85.7, \mathrm{UF}$ $=98.8 ; P=0.09)$. Concordantly, the survival analyses (Figure 2) did not indicate a significant difference on the time from calving to first AI $(P=0.08)$. Pregnancy at first postpartum AI was 23.0 and $37.8 \%$ in the CON and UF groups, respectively $(P=0.05)$. Pregnancy at first postpartum AI was $39.3 \%$ in $\mathrm{HC}$ cows and this value was different to those from $\mathrm{CON}$ and UF cows $(P=0.02)$.

Pregnancy at 150 and 300 DIM. Overall, 300 (75\%) HC cows were pregnant by 150 DIM, whereas 34 cows $(30.1 \%)$ in the CON group and 48 cows (44.8\%) in the UF group were pregnant by 150 DIM. When only cows that had received at least 1 AI by 150 DIM were included, the percentages of pregnant cows by 150 DIM were $81.1,53.1$, and $72.7 \%$ for the $\mathrm{HC}, \mathrm{CON}$, and $\mathrm{UF}$ groups respectively.

By 300 DIM, 360 (90\%) HC cows, 50 cows (44.3\%) in the CON group, and 63 cows $(58.9 \%)$ in UF group were pregnant. When only cows that had received at least 1 AI by 300 DIM were included the percentages of pregnant cows by 150 DIM were $92.6,80.7$, and $72.4 \%$ for the $\mathrm{HC}, \mathrm{CON}$, and UF groups respectively.

Consequently, treatment was significantly associated with pregnancy at 150 and at 300 DIM. The odds of pregnancy at 150 DIM for cows in the UF group were $1.81(95 \% \mathrm{CI}=1.04-3.15)$ times the odds of cows in 


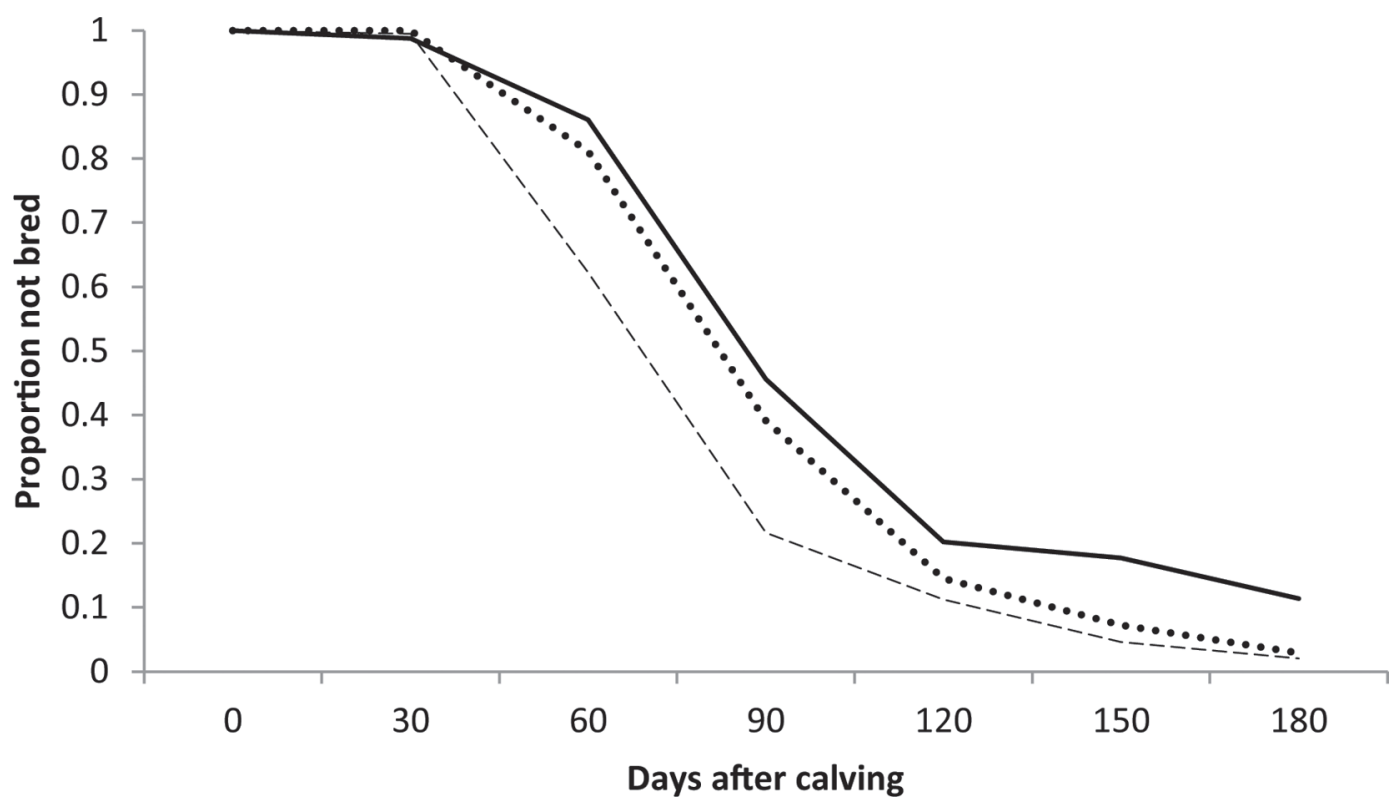

Figure 2. Survival curves for the interval from calving to first AI by treatment group. Mean for days from calving to first AI were control $(\mathrm{CON})=85.7$ and Optimum UterFlush (UF; Van Beek Natural Science, Orange City, IA $)=98.8(P=0.09)$. Adjusted hazard ratio $=0.74($ UF vs. CON treatment, $P=0.07$ ). The CON group (...) received $200 \mathrm{~mL}$ of povidone iodine diluted in $2 \mathrm{~L}$ of distilled water (i.u.); the UF group $(-)$ received $3.75 \mathrm{~mL}$ diluted in $117 \mathrm{~mL}$ of distilled water (i.u.). The healthy control group (- - -), consisting of cows calving during the same period without any postpartum disorder, is included as a reference for comparison.

Table 5. Results from the multivariable logistic regression analyses for reproductive outcomes; only treatment and variables with $P<0.10$ are presented

\begin{tabular}{|c|c|c|c|}
\hline Variable & $\mathrm{OR}^{1}$ & $95 \% \mathrm{CI}$ & $P$-value \\
\hline \multicolumn{4}{|c|}{ AI <150 DIM } \\
\hline \multicolumn{4}{|c|}{ Treatment $^{2}$} \\
\hline UF & 1.36 & $0.77-2.41$ & 0.27 \\
\hline $\mathrm{CON}$ & Referent & - & - \\
\hline \multicolumn{4}{|c|}{ BCS at enrollment } \\
\hline$>2.5$ & 2.40 & $1.31-4.61$ & 0.008 \\
\hline$<2.5$ & Referent & - & - \\
\hline \multicolumn{4}{|c|}{$\begin{array}{l}\text { Pregnancy at first } \\
\text { insemination }\end{array}$} \\
\hline \multicolumn{4}{|c|}{ Treatment } \\
\hline UF & 2.15 & $1.05-4.40$ & 0.003 \\
\hline $\mathrm{CON}$ & Referent & - & - \\
\hline \multicolumn{4}{|c|}{ Pregnancy at 150 DIM } \\
\hline \multicolumn{4}{|c|}{ Treatment } \\
\hline UF & 1.81 & $1.04-3.15$ & 0.03 \\
\hline $\mathrm{CON}$ & Referent & - & - \\
\hline \multicolumn{4}{|c|}{ Pregnancy at 300 DIM } \\
\hline \multicolumn{4}{|c|}{ Treatment } \\
\hline UF & 1.92 & $1.09-3.38$ & 0.02 \\
\hline $\mathrm{CON}$ & Referent & - & - \\
\hline \multicolumn{4}{|c|}{ BCS at enrollment } \\
\hline$>2.5$ & 1.81 & $0.93-3.51$ & 0.07 \\
\hline$\leq 2.5$ & Referent & - & - \\
\hline
\end{tabular}

${ }^{1}$ Odds ratio.

${ }^{2} \mathrm{UF}=$ Optimum UterFlush (Van Beek Natural Science, Orange City, IA) group, receiving $3.75 \mathrm{~mL}$ diluted in $117 \mathrm{~mL}$ of distilled water (i.u.); $\mathrm{CON}=$ control group, receiving $200 \mathrm{~mL}$ of povidone iodine diluted in $2 \mathrm{~L}$ of distilled water (i.u.). the CON group. Similarly, the odds of pregnancy at 300 DIM for cows in the UF group were 1.92 (95\% CI $=1.09-3.38)$ times the odds of cows in the CON group (Table 5). In cows that conceived, least squares means for the number of days to pregnancy were 136.1 and $124.8 \mathrm{~d}$ for CON and UF groups, respectively $(P=$ $0.35)$. However, when censored cows were considered in the multivariable survival analysis, a significant effect for treatment on time to pregnancy was found $(P=0.02$, Figure 3$)$. Similarly, the number of AI per pregnancy was lower for the UF group (2.02) compared with the CON group (2.69).

\section{Clinical Outcome Variables and Reproductive Performance}

The probability of receiving AI before 150 DIM was significantly associated with fever at d $6, \operatorname{VDS}$ at $\mathrm{d} 6$, and UTS at d 6 and 14 (Table 6). There was a trend $(P=0.09)$ for an association between the probability of pregnancy at the first AI and the UTS at d 6. However, UTS at d 14 was significantly associated with the probability of pregnancy at the first AI. The probability of pregnancy at 150 DIM was significantly associated with RT at d 6 and UTS at d 6 and 14. Finally, the probability of pregnancy at 300 DIM was significantly associated with RT at d 6, VDS at d 6, and UTS at d 6 and 14. 


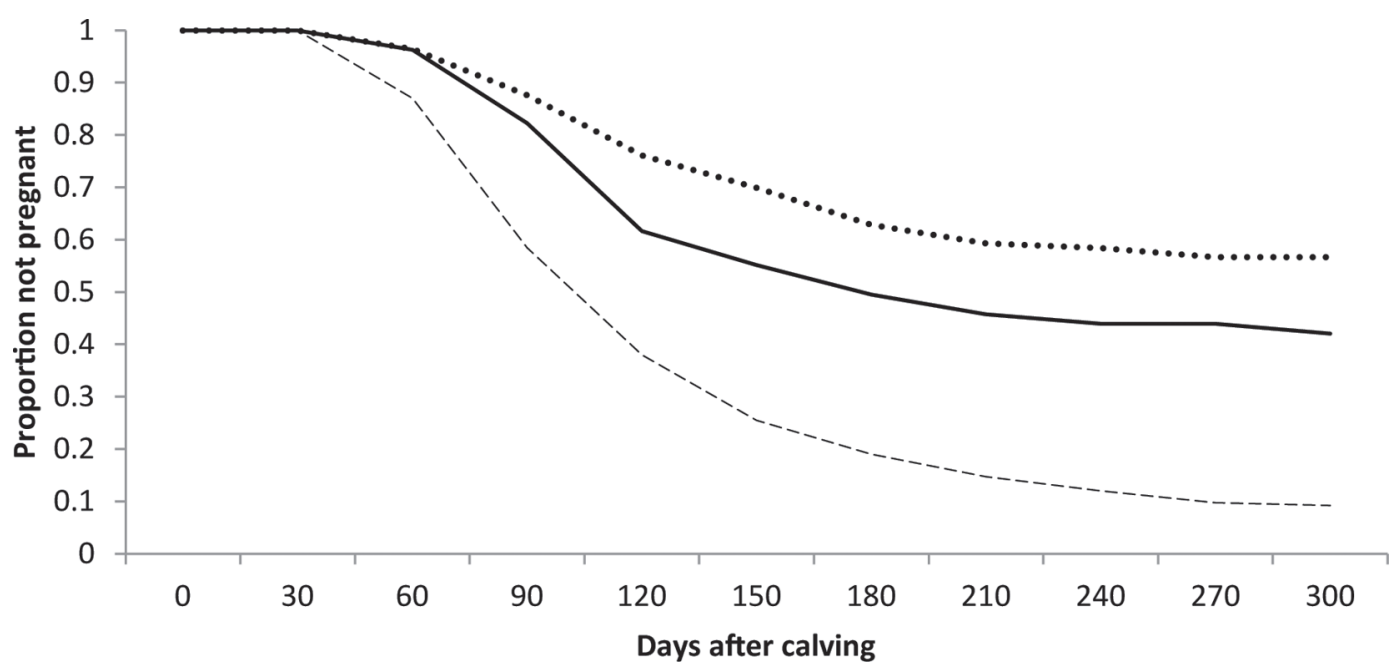

Figure 3. Survival curves for the interval from calving to pregnancy by treatment group. Least squares means for days from calving to pregnancy were control $(\mathrm{CON})=136.1$ and Optimum UterFlush (UF; Van Beek Natural Science, Orange City, IA $)=124.8(P=0.35)$. Adjusted hazard ratio $=1.53$ (UF vs. $\mathrm{CON}$ treatment, $P=0.02$ ). The CON group $(\ldots .$.$) received 200 \mathrm{~mL}$ of povidone iodine diluted in $2 \mathrm{~L}$ of distilled water (i.u.); the UF group (-) received $3.75 \mathrm{~mL}$ diluted in $117 \mathrm{~mL}$ of distilled water (i.u.). The healthy control group (- - -), consisting of cows calving during the same period without any postpartum disorder, is included as a reference for comparison.

\section{DISCUSSION}

The distribution of bacteria isolated from uterine fluid samples in our study is in partial agreement with previous reports. Sannmann et al. (2013) indicated that the most prevalent pathogens from uteri of cows with TPM were E. coli, followed by $T$. pyogenes and Fusobacterium necrophorum. Similarly, Williams et al. (2005) reported T. pyogenes and E. coli within the most common pathogens isolated from uteri of periparturient cows. However, several other pathogenic microorganisms, such as Prevotella melaninogenicus, Bacteroides spp., Pseudomonas spp., Streptococcus spp., and Staphylococcus spp., under multiple combinations, have been isolated from infected uteri of metritic cows and are thought to be responsible for puerperal metritis (Huszenicza et al., 1999; Williams et al., 2005; Azawi, 2008; Santos et al., 2011).

A reduced subpopulation of our study cows had paired bacteriological samples (study d 0 and 14). From those, only a proportion (10/29) of cows cleared T. pyogenes infection at $\mathrm{d} 14$. Interestingly, for $E$. coli, all the cows with paired samples cleared infection (8/8) but 3 cows that were negative at enrollment were $E$. coli positive at d 14 . In both cases, no difference by treatment was determined.

Consistent with our case definition, all enrolled cows were febrile at enrollment. In both groups, RT decreased gradually from d 0 to 14 . However, cows in the UF group had a more pronounced decrease on RT during the first $4 \mathrm{~d}$ after enrollment. Nevertheless, average temperatures for both groups converged at d 6 and 14
(Figure 1). A similar daily trend for RT in cows affected with TPM was presented by Benzaquen et al. (2007). Cows in that study had a decrease in $\mathrm{RT}$ relative to the previous day of 0.6 and $0.3^{\circ} \mathrm{C}$ at $\mathrm{d} 1$ and 2 after treatment with ceftiofur hydrochloride (i.m.). McLaughlin et al., (2012) presented a reduction of about $0.55^{\circ} \mathrm{C}$ in RT for metritic cows after $1 \mathrm{~d}$ of ceftiofur hydrochloride treatment. A similar response was reported by Lima et al. (2014), where TPM cows treated with ampicillin trihydrate (i.m.) or ceftiofur hydrochloride (i.m.) had a significant reduction in RT after the first day of treatment $\left(0.6\right.$ and $0.5^{\circ} \mathrm{C}$, respectively). Likewise, groups of cows with TPM administered 3 different treatments [ceftiofur (i.m.), ampicillin and cloxacillin (i.u.) plus ampicillin (i.m.), and ampicillin and cloxacillin (i.u.) plus ceftiofur (i.m.)] resulted in an absence of fever in $82.9,84.8$, and $84.6 \%$ of cases at d 6 after beginning of treatment (Drillich et al., 2001). It is interesting to note that a decline in RT in metritic cows that remained untreated has been reported, indicating spontaneous recovery (Chenault et al., 2004; McLaughlin et al., 2012; Sannmann et al., 2013).

Recovery rates for VDS $(<4)$ at d 6 and 14 were high in both treatment groups. More than $90 \%$ of the cows in both treatment groups had VDS $<4$ by study d 14 . Chenault et al. (2004) reported VDS (scores from 0-4) decreasing, nearly linearly, to a mean of 2.5 by study d 14 in TPM cows administered saline solution (control group) or systemic ceftiofur treatment [1.1 and $2.2 \mathrm{mg}$ of ceftiofur equivalents $(\mathbf{C E}) / \mathrm{kg}]$. A recent study using a similar criterion for evaluation of VDS, reported that more than $80 \%$ of cows with metritis treated with 
Table 6. Results from the multivariable logistic regression analysis testing the effect of clinical outcome variables at study d 6 and 14 on reproductive outcomes; only variables with $P<0.10$ are presented

\begin{tabular}{|c|c|c|c|c|c|c|}
\hline \multirow[b]{2}{*}{ Variable } & \multicolumn{3}{|c|}{ d 6} & \multicolumn{3}{|c|}{ d 14} \\
\hline & $\mathrm{OR}^{1}$ & $95 \%$ CI & $P$-value & OR & $95 \% \mathrm{CI}$ & $P$-value \\
\hline \multicolumn{7}{|c|}{$\mathrm{AI}<150$ DIM } \\
\hline \multicolumn{7}{|c|}{ Rectal temperature } \\
\hline$<39.5^{\circ} \mathrm{C}$ & 2.11 & $1.11-4.03$ & 0.02 & - & - & - \\
\hline$\geq 39.5^{\circ} \mathrm{C}$ & Referent & - & - & - & - & - \\
\hline \multicolumn{7}{|l|}{$\mathrm{VDS}^{2}$} \\
\hline$<4$ & 2.25 & $1.12-4.54$ & 0.02 & - & - & - \\
\hline 4 & Referent & - & - & - & - & - \\
\hline \multicolumn{7}{|l|}{$\mathrm{UTS}^{3}$} \\
\hline 2 & 2.91 & $1.39-6.09$ & 0.004 & 2.76 & $1.36-5.58$ & 0.004 \\
\hline 1 & Referent & - & - & - & - & - \\
\hline \multicolumn{7}{|c|}{ Pregnancy at first insemination } \\
\hline \multicolumn{7}{|c|}{ UTS } \\
\hline 2 & 1.82 & $0.89-3.77$ & 0.09 & 2.88 & $1.10-7.51$ & 0.03 \\
\hline 1 & Referent & - & - & - & - & - \\
\hline \multicolumn{7}{|c|}{ Pregnancy at 150 DIM } \\
\hline \multicolumn{7}{|c|}{ Rectal temperature } \\
\hline$<39.5^{\circ} \mathrm{C}$ & 2.59 & $1.28-5.24$ & 0.008 & - & - & - \\
\hline$\geq 39.5^{\circ} \mathrm{C}$ & Referent & - & - & - & - & - \\
\hline \multicolumn{7}{|l|}{ VDS } \\
\hline$<4$ & 1.96 & $0.90-4.26$ & 0.09 & - & - & - \\
\hline 4 & Referent & - & - & - & - & - \\
\hline \multicolumn{7}{|l|}{ UTS } \\
\hline 2 & 2.38 & $1.27-4.44$ & 0.006 & 4.41 & $2.07-9.34$ & 0.0001 \\
\hline 1 & Referent & — & - & - & - & — \\
\hline \multicolumn{7}{|c|}{ Pregnancy at 300 DIM } \\
\hline \multicolumn{7}{|c|}{ Rectal temperature } \\
\hline$<39.5^{\circ} \mathrm{C}$ & 2.86 & $1.48-5.53$ & 0.002 & - & - & - \\
\hline$\geq 39.5^{\circ} \mathrm{C}$ & Referent & - & - & - & - & - \\
\hline \multicolumn{7}{|l|}{ VDS } \\
\hline$<4$ & 2.6 & $1.24-5.45$ & 0.011 & - & - & - \\
\hline 4 & Referent & - & - & - & - & - \\
\hline \multicolumn{7}{|l|}{ UTS } \\
\hline 2 & 2.94 & $1.51-5.71$ & 0.001 & 6.25 & $2.78-12.5$ & 0.001 \\
\hline 1 & Referent & - & - & - & - & - \\
\hline
\end{tabular}

systemic antibiotic cleared fetid discharge by d 12 after diagnosis (Lima et al., 2014). As pointed out in that report, an aggressive monitoring program, resulting in early diagnosis and prompt treatment, may accelerate the recovery of sick animals. Notably, other reports have indicated that cows with TPM that remained untreated had a similar improvement in VDS compared with cows receiving $2.2 \mathrm{mg} / \mathrm{kg}$ of ceftiofur for 3 consecutive days (Giuliodori et al., 2013).

Clinical cure (absence of fever and VDS $<4$ ) at $\mathrm{d}$ 6 was significantly different between treatments, at 48.7 and $70.1 \%$ for cows in the CON and UF groups, respectively. However, at d 14 this difference was not significant, with 65.5 and $75.7 \%$ of the cows in the CON and UF groups recovered, respectively. Similar values were presented by Lima et al. (2014), who reported 66.1 and $67.4 \%$ clinical cure (absence of fever and VDS $<4$ ) at d 12 for TPM cows receiving systemic treatment with ampicillin trihydrate or ceftiofur hydrochloride. In the study by Chenault et al. (2004), clinical cure rates were significantly greater for both the $2.2 \mathrm{mg}$ of $\mathrm{CE} / \mathrm{kg}(41 \%)$ and the $1.1 \mathrm{mg}$ of $\mathrm{CE} / \mathrm{kg}(37 \%)$ treatment groups, compared with clinical cure rates of the control group (29\%). Regarding studies including an untreated control group, a recent review by Haimerl and Heuwieser (2014) indicated that 7 out of the 21 studies considered reported self-cure rates for their TPM untreated control groups, with an average cure rate without any treatment of $36.9 \%$ (range: 16-62\%).

Uterine involution, defined as the process associated with the return of the postpartum uterus to the state of initiating and supporting another pregnancy (Zemjanis, 1970), is concluded around $45 \mathrm{~d}$ postpartum and consists of the reduction in size, loss of tissue, and tis- 
sue regeneration of the uterus (Kiracofe, 1980). The difference in uterine tonicity and size might be a reflection of uterine contractility, reduction of uterine diameter, and shorter time until anatomical involution (Slama et al., 1991; Hirsbrunner et al., 2002). In agreement with our results, Melendez et al. (2004) reported an interaction between treatment and parity that affected uterine horn diameter of cows with TPM; in both studies treatment had an effect only in primiparous cows. Multiple physiological differences between primiparous and multiparous cows may explain this finding, including a higher incidence of hypocalcemia in multiparous cows (Goff and Horst, 1997).

Due to well-being considerations, it was not possible to have a nontreated control group and, consequently, we used a positive control consisting of the routine treatment for TPM that the study farm has used for the last $7 \mathrm{yr}$. However, a true test of effectiveness cannot be concluded from studies by the use of a positive control. To allow for a reference for comparison of the effect of TPM on survival end reproductive performance, we included a healthy control group consisting of cows calving during the study period but that were not affected by metritis. Given that the study farm is a commercial operation and considering the well-being of the affected cows, the supportive therapy that was in place in this farm was maintained in our study population. Although this factor probably increased the recovery rate of the study population when compared with negative controls in other studies, having the same treatment applied to all enrolled cows reduced the risk of favoring one of the treatment groups.

Ninety seven percent of the cows in the $\mathrm{HC}$ group survived at 100 DIM. This high value may be in part explained by our group selection criteria including absence of reproductive disease and a significant proportion of primiparous cows $(62 \%)$ to match the study population. In comparison, survival was significantly lower for the TPM-affected population, with 70.8 and $80.4 \%$ of the cows in the CON and UF groups, respectively, present in the farm at 100 DIM. Nevertheless, treatment had an effect on survival: cows in the UF group had higher odds of survival at 100 DIM compared with cows in the CON group.

The effect of treatment on first AI was partial; no difference was found in both the probability of AI at 150 DIM or in the number of days to first AI for both treatment groups. However, cows in the UF group had a higher probability of AI at 300 DIM and a higher probability of pregnancy at first AI. Treatment had a significant effect in favor of the UF group in both probabilities of pregnancy at 150 and 300 DIM. Conversely, cows in the HC group had a significantly better reproductive performance when compared with both groups of TPM cows. In partial agreement, a previous study reported different antibiotic treatments that resulted in similar values for pregnancy at first AI when compared with untreated metritis cows (Lima et al., 2014). Contrary to our results, Rabaglino et al. (2009) reported no difference in pregnancy at the first postpartum timed AI when cows without metritis $(33.3 \%)$ were compared with cows diagnosed and treated for metritis (29.9\%). Interestingly, when cows diagnosed with metritis treated with chlortetracycline as intrauterine boluses were compared with untreated controls, the $\mathrm{P} / \mathrm{AI}$ at first postpartum insemination were $38.3,42.5$, and $18 \%$ in cows without metritis, cows with metritis treated with chlortetracycline, and cows with metritis that remained as untreated controls, respectively (Goshen and Shpigel, 2006). Moreover, Benzaquen et al. (2007) reported no difference in the first-service pregnancy risk and the pregnancy risk at 150 DIM between normal cows and cows with puerperal metritis; no difference was also found for calving-to-first-AI interval and calving-topregnancy intervals.

All the clinical variables evaluated for TPM in our study had an effect on at least 1 reproductive parameter. Fever and VDS at d 6 affected multiple parameters, including the probability of AI and pregnancy before 150 and 300 DIM. The same parameters plus pregnancy at first insemination were affected by UTS at $\mathrm{d} 6$ and 14 .

The negative effect of these clinical signs has been reported previously. A detrimental effect of purulent vaginal discharge was reported by Dubuc et al. (2011), where affected cows had a reduced risk of pregnancy (hazard ratio $=0.72$ ). In a study by Giuliodori et al. (2013), cows with puerperal metritis, compared with healthy controls, had lower risk for pregnancy by 100 DIM, a lower hazard rate for pregnancy by 150 DIM, and took longer to get pregnant.

However, other reports have failed to demonstrate associations between the presence of metritis and reproductive performance (Benzaquen et al., 2007; Rabaglino et al., 2009; Lima et al., 2014). In those studies, the authors speculate about the possibility that an early diagnosis and prompt therapy might have minimized the negative effect of metritis on fertility.

As pointed out by Melendez et al. (2004), uterine tone has been barely evaluated as an outcome variable in clinical trials conducted on dairy cattle as the method is highly subjective. However, using a well-defined scoring system, usefulness of uterine tonicity might have practical implications. In the study of Melendez et al. (2004), cows with smaller uterine diameters $(<5.1 \mathrm{~cm})$ had greater pregnancy rate at first service (30.8 vs. $7.9 \%$, respectively) than cows with a uterine diameter $\geq 5.1 \mathrm{~cm}$. This finding is consistent with other studies 
that reported uterine diameter during the postpartum period was associated with reduced fertility (LeBlanc et al., 2002) and may be related to the detrimental effect that UTS 1 showed on reproductive outcomes in our study.

\section{CONCLUSIONS}

No treatment effect was observed on the occurrence of fever at study d 6 and 14. However, presence of a fetid vaginal discharge at d 6 and 14 was significantly lower in UF cows compared with CON cows. The odds for survival and remaining on the farm at study d 6 and 14 and at 30 and 100 DIM for cows in the UF group were between 2 to 4 times the odds of cows in the CON treatment. The probability of AI until 150 DIM and the interval from calving to first AI were not different between the 2 treatments, but the risk of pregnancy was affected by treatment; the odds of pregnancy at the first AI or at 150 and 300 DIM for cows treated with Optimum UterFlush were significantly higher than those of cows in the CON group. Overall, results indicate that cows with TPM administered intrauterine infusion of Optimum UterFlush had higher odds of recovering and improved reproductive performance compared with cows treated with povidone iodine. Further research is needed to identify potential safety limitations and precise milk and meat withdrawal times associated with the use of Optimum UterFlush.

\section{REFERENCES}

Azawi, O. I. 2008. Postpartum uterine infection in cattle. Anim. Reprod. Sci. 105:187-208.

Bartlett, P. C., J. H. Kirk, M. A. Wilke, J. B. Kaneene, and E. C. Mather. 1986. Metritis complex in Michigan Holstein-Friesian cattle: Incidence, descriptive epidemiology and estimated economic impact. Prev. Vet. Med. 4:235-248.

Baser, K. H. 2008. Biological and pharmacological activities of carvacrol and carvacrol bearing essential oils. Curr. Pharm. Des. 14:3106-3119.

Benzaquen, M. E., C. A. Risco, L. F. Archbald, P. Melendez, M. J. Thatcher, and W. W. Thatcher. 2007. Rectal temperature, calving-related factors, and the incidence of puerperal metritis in postpartum dairy cows. J. Dairy Sci. 90:2804-2814.

Chapinal, N., M. Carson, T. F. Duffield, M. Capel, S. Godden, M. Overton, J. E. P. Santos, and S. J. LeBlanc. 2011. The association of serum metabolites with clinical disease during the transition period. J. Dairy Sci. 94:4897-4903.

Chenault, J. R., J. F. McAllister, S. T. Chester, K. J. Dame, F. M. Kausche, and E. J. Robb. 2004. Efficacy of ceftiofur hydrochloride sterile suspension administered parenterally for the treatment of acute postpartum metritis in dairy cows. J. Am. Vet. Med. Assoc. 224:1634-1639.

Drillich, M., O. Beetz, A. Pfutzner, M. Sabin, H. J. Sabin, P. Kutzer, H. Nattermann, and W. Heuwieser. 2001. Evaluation of a systemic antibiotic treatment of toxic puerperal metritis in dairy cows. J. Dairy Sci. 84:2010-2017.

Dubuc, J., T. F. Duffield, K. E. Leslie, J. S. Walton, and S. J. LeBlanc. 2011. Randomized clinical trial of antibiotic and prostaglan- din treatments for uterine health and reproductive performance in dairy cows. J. Dairy Sci. 94:1325-1338.

Ferguson, J. D., D. T. Galligan, and N. Thomsen. 1994. Principal descriptors of body condition score in Holstein cows. J. Dairy Sci. 77:2695-2703.

Friedman, M. 2014. Chemistry and multibeneficial bioactivities of carvacrol (4-isopropyl-2-methylphenol), a component of essential oils produced by aromatic plants and spices. J. Agric. Food Chem. ; Epub ahead of print.

Gilbert, R. O., S. T. Shin, C. L. Guard, H. N. Erb, and M. Frajblat. 2005. Prevalence of endometritis and its effects on reproductive performance of dairy cows. Theriogenology 64:1879-1888.

Giuliodori, M. J., R. P. Magnasco, D. Becu-Villalobos, I. M. LacauMengido, C. A. Risco, and R. L. de la Sota. 2013. Metritis in dairy cows: Risk factors and reproductive performance. J. Dairy Sci. 96:3621-3631.

Goff, J. P., and R. L. Horst. 1997. Physiological changes at parturition and their relationship to metabolic disorders. J. Dairy Sci. 80:1260-1268.

Goshen, T., and N. Y. Shpigel. 2006. Evaluation of intrauterine antibiotic treatment of clinical metritis and retained fetal membranes in dairy cows. Theriogenology 66:2210-2218.

Haimerl, P., and W. Heuwieser. 2014. Invited review: Antibiotic treatment of metritis in dairy cows: A systematic approach. J. Dairy Sci. 97:6649-6661.

Hirsbrunner, G., B. Knutti, I. Liu, U. Küpfer, G. Scholtysik, and A. Steiner. 2002. An in vivo study on spontaneous myometrial contractility in the cow during estrus and diestrus. Anim. Reprod. Sci. 70:171-180.

Huszenicza, G., M. Fodor, M. Gacs, M. Kulcsar, M. J. W. Dohmen, M. Vamos, L. Porkolab, T. Kegl, J. Bartyik, J. A. C. M. Lohuis, S. Janosi, and G. Szita. 1999. Uterine bacteriology, resumption of cyclic ovarian activity and fertility in postpartum cows kept in large-scale dairy herds. Reprod. Domest. Anim. 34:237-245.

Kasimanickam, R., T. F. Duffield, R. A. Foster, C. J. Gartley, K. E. Leslie, and J. S. Walton. 2004. Endometrial cytology and ultrasonography for the detection of subclinical endometritis in postpartum dairy cows. Theriogenology 62:9-23.

Kiracofe, G. H. 1980. Uterine involution: Its role in regulating postpartum intervals. J. Anim. Sci. 51(Suppl. 2):16-28.

LeBlanc, S. J. 2008. Postpartum uterine disease and dairy herd reproductive performance: A review. Vet. J. 176:102-114.

LeBlanc, S. J., T. F. Duffield, K. E. Leslie, K. G. Bateman, G. P. Keefe, J. S. Walton, and W. H. Johnson. 2002. Defining and diagnosing postpartum clinical endometritis and its impact on reproductive performance in dairy cows. J. Dairy Sci. 85:2223-2236.

Lima, F. S., A. Vieira-Neto, G. S. F. M. Vasconcellos, R. D. Mingoti, E. Karakaya, E. Solé, R. S. Bisinotto, N. Martinez, C. A. Risco, K. N. Galvão, and J. E. P. Santos. 2014. Efficacy of ampicillin trihydrate or ceftiofur hydrochloride for treatment of metritis and subsequent fertility in dairy cows. J. Dairy Sci. 97:5401-5414.

Lima, M. S., L. J. Quintans-Júnior, W. A. de Santana, C. Martins Kaneto, M. B. Pereira Soares, and C. F. Villarreal. 2013. Antiinflammatory effects of carvacrol: Evidence for a key role of interleukin-10. Eur. J. Pharmacol. 699:112-117.

McBride, W. D., and C. Greene. 2009. Characteristics, costs, and issues for organic dairy farming, ERR-82, U.S. Department of Agriculture, Economic Research Service. Accessed Feb.20, 2015. http://www.ers.usda.gov/publications/err-economic-research-report/err82.aspx.

McLaughlin, C. L., E. Stanisiewski, M. J. Lucas, C. P. Cornell, J. Watkins, L. Bryson, J. K. S. Tena, J. Hallberg, and J. R. Chenault. 2012. Evaluation of two doses of ceftiofur crystalline free acid sterile suspension for treatment of metritis in lactation dairy cows. J. Dairy Sci. 95:4363-4371.

Melendez, P., J. McHale, J. Bartolome, L. F. Archbald, and G. A. Donovan. 2004. Uterine involution and fertility of Holstein cows subsequent to early postpartum $\mathrm{PGF}_{2 \alpha}$ treatment for acute puerperal metritis. J. Dairy Sci. 87:3238-3246.

National Research Council. 2001. Nutrient Requirements of Dairy Cattle. 7th rev. ed. National Academies Press, Washington DC. 
National Standard of Canada. 2013. Organic Production Systems. General principles and management standards. CAN/CGSB32.310-2006. Accessed Feb. 21, 2015. http://www.tpsgc-pwgsc. gc.ca/ongc-cgsb/programme-program/normes-standards/internet/bio-org/principes-principles-eng.html.pdf.

Pol, M., and P. L. Ruegg. 2007. Treatment practices and quantification of antimicrobial drug usage in conventional and organic dairy farms in Wisconsin. J. Dairy Sci. 90:249-261.

Rabaglino, M. B., J. E. P. Santos, C. Fuentes, and C. A. Risco. 2009. Milk production and reproductive performance in postpartum dairy cows diagnosed and treated for metritis using a health monitoring program. Page 216 in Proc. 42nd Conf. Am. Assoc. Bovine. Pract. American Association of Bovine Practitioners, Omaha, NE.

Ruegg, P. L. 2009. Management of mastitis on organic dairy farms. J. Anim. Sci. 87:43-55.

Sannmann, I., O. Burfeind, R. Voigtsberger, and W. Heuwieser. 2013. Comparison of two monitoring and treatment strategies for cows with acute puerperal metritis. Theriogenology 79:961-969.

Santos, J. E. P., R. S. Bisinotto, E. S. Ribeiro, F. S. Lima, L. F. Greco, C. R. Staples, and W. W. Thatcher. 2010. Applying nutrition and physiology to improve reproduction in dairy cattle. Soc. Reprod. Fertil. Suppl. 67:387-403.

Santos, T. M. A., R. O. Gilbert, and R. C. Bicalho. 2011. Metagenomic analysis of the uterine bacterial microbiota in healthy and metritic postpartum dairy cows. J. Dairy Sci. 94:291-302.
Sheldon, I. M., and H. Dobson. 2004. Postpartum uterine health in cattle. Anim. Reprod. Sci. 82-83:295-306.

Sheldon, I. M., G. S. Lewis, S. LeBlanc, and R. O. Gilbert. 2006. Defining postpartum uterine disease in cattle. Theriogenology 65:1516-1530

Slama, H., D. Vaillancourt, and A. K. Goff. 1991. Pathophysiology of the puerperal period: Relationship between prostaglandin E2 (PGE2) and uterine involution in the cow. Theriogenology 36:1071-1090

Suntres, Z. E., J. Coccimiglio, and M. Alipour. 2015. The bioactivity and toxicological actions of carvacrol. Crit. Rev. Food Sci. Nutr. $55: 304-318$.

Williams, E. J., D. P. Fischer, D. U. Pfeiffer, G. C. England, D. E. Noakes, H. Dobson, and I. M. Sheldon. 2005. Clinical evaluation of postpartum vaginal mucus reflects uterine bacterial infection and the immune response in cattle. Theriogenology 63:102-117.

Zemjanis, R. 1970. Examination of the cow. Pages 3-87 in Diagnostic and Therapeutic Techniques in Animal Reproduction. 2nd ed. R. Zemjanis, ed. The Williams \& Wilkins Company, Waverly Press Inc., Baltimore, MD 